\title{
Supplemental Calories Improve Essential Fatty Acid Deficiency in Cystic Fibrosis Patients
}

\author{
H. G. PARSONS, E. V. O'LOUGHLIN, D. FORBES, D. COOPER, AND D. G. GALL \\ G.I. Research Group, Divisions of Gastroenterology and Nutrition and Pulmonary Department of Pediatrics, \\ University of Calgary and Alberta Children's Hospital, Calgary, Alberta, Canada
}

\begin{abstract}
Fatty acid composition of plasma lipids was analyzed in malnourished cystic fibrosis patients undergoing 6 months of nutritional rehabilitation. There were three males and five females (mean age $15.1 \mathrm{yr}$ ); five patients had pancreatic insufficiency. Nutritional rehabilitation in seven of eight patients was accomplished by nocturnal nasogastric infusion of a high-carbohydrate semisynthetic diet, in addition to daily meals. One patient received highenergy food supplements as snacks in addition to regular meals. All patients were moderately to severely malnourished on entry to the study and showed significant improvement over the 6 months in ( $\ddot{\mathrm{x}} \pm \mathrm{SE})$ energy intake $(96 \pm$ 8.0 to $126 \pm 11 \%$ recommended daily allowance) and body composition ( $80 \pm 4$ to $90 \pm 4 \%$ ideal body weight). Daily intakes of linoleic acid were not significantly different before or during nutritional rehabilitation either as an absolute amount ( $383 \pm 45$ to $557 \pm 124 \mathrm{mg} / \mathrm{kg} /$ day $)$ or as a percentage of total calories $(4.50 \pm 0.40$ to $4.73 \pm 0.14 \%)$. In comparison to the controls, the relative percentage of plasma cholesterol ester fatty acids of the CF patients on entry into the study showed a marked decrease of linoleic acid $(52.7 \pm 1.0$ versus $42.3 \pm 2.7 \%)$ with elevated palmitoleic $(2.34 \pm 0.2$ versus $5.64 \pm 0.7 \%)$ and oleic $(18.7 \pm$ 1.0 versus $25.2 \pm 1.4 \%$ ) acids; a pattern consistent with essential fatty acid deficiency. However, this pattern is not truly characteristic of a pure linoleic acid deficiency as the metabolites of linoleic acid were not decreased. After nutritional rehabilitation the linoleic acid concentration reached control values in the phospholipid and cholesterol ester plasma lipids in six of eight and five of eight patients, respectively. These findings indicate a low caloric intake is an important factor in determining the essential fatty acid status of cystic fibrosis patients and recovery of both the body composition and essential fatty acid deficiency can be accomplished by increasing the caloric intake to $150 \%$ of recommended daily allowances. (Pediatr Res 24: $353-356,1988$ )
\end{abstract}

\section{Abbreviations}

EFA, essential fatty acid

CF, cystic fibrosis

RDA, recommended daily allowance

Many investigators have described a high incidence of biochemical EFA deficiency in CF patients (1-5). These patients

Received May 11, 1987; accepted January 11, 1988.

Correspondence Dr. H. G. Parsons, University of Calgary, Faculty of Medicine, Department of Pediatrics, 3330 Hospital Drive N.W., Calgary, Alberta, T2N 4N1, Canada.

Supported by a grant from the Canadian Cystic Fibrosis Foundation.

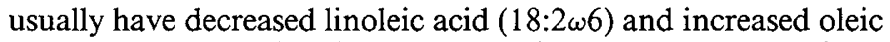
$(18: 1 \omega 9)$ and palmitoleic $(16: 1 \omega 9)$ acids. Several mechanisms have been suggested for the abnormal fatty acid pattern, including 1 ) part of the primary genetic defect of CF $(6,7) ; 2)$ dietary deficiency and/or malabsorption of EFA secondary to pancreatic insufficiency (3); 3) abnormal metabolism of linoleic acid to its metabolites $(6,8)$; and 4 ) energy malnutrition with oxidation of linoleic acid for ATP production (9). This study examines the role of caloric supplementation for the correction of EFA deficiency in malnourished $\mathrm{CF}$ patients.

Malnutrition, characterized by decreased growth or decreased weight for height, is a common finding in CF patients (10). The malnutrition results from energy intake below requirement (11), increased stool energy losses, and/or increased metabolic energy needs $(12,13)$. Abnormalities in plasma EFA status have been previously associated with malnutrition syndromes such as anorexia nervosa (14), marasmus (15), and kawshiorkor $(16,17)$. Recent technological advances allow the nutritional status of malnourished CF patients to be normalized and hence permit clarification of the effects of malnutrition on plasma EFA of $C F$ patients.

\section{METHODS}

The study population consisted of eight CF patients who met the following selection criteria: 1 ) weight and/or height less than the 3rd percentile for age; 2) persistent fall in weight percentile over the previous 12 months, and 3) age more than 6 yr (to facilitate compliance). All patients had clinical findings indicative of $\mathrm{CF}$ and elevated sweat electrolytes. This study was approved by the Ethics Committee of the University of Calgary and patients and/or parents gave written informed consent.

The patients commenced a 6-month period of nutrient supplementation designed to achieve $150 \%$ of their RDA for calories. All patients received a standard North American diet. Seven patients received supplementation by nocturnal nasogastric feeds of a semisynthetic formula (Vital, Ross Laboratories, Montreal, Quebec, Canada). This formula provided $16.7 \%$ of calories as protein, $9.3 \%$ as fat, and $74.0 \%$ as carbohydrate. Therapy was initiated in hospital and continued at home. A silastic nasogastric tube was inserted each night and the formula infused at 100-150 $\mathrm{ml} / \mathrm{h}$ over 8 to $10 \mathrm{~h}$. Nonenteric-coated pancreatic enzymes (Cotazym, Organon, Ontario, Canada) were added to the formula, 1 capsule $/ 300 \mathrm{ml}$, for those patients with pancreatic insufficiency. The 8 th patient achieved $150 \%$ of the RDA for calories by ingestion of high-energy food supplements in addition to regular meals. Routine vitamins and physiotherapy were continued. Patients were assessed by the clinic physician, study coordinator, and dietitian at 2 -month intervals. Antibiotic therapy was begun if sputum production increased and pulmonary function deteriorated.

Seven-day dietary records were analyzed (NUTS Nutrition Assessment System, Version 2, Quilchena Consulting Ltd., Vic- 
toria, B.C., Canada) for dietary composition, including linoleic acid, at 2-month intervals. Body composition was determined by deuterium dilution (18). Deuterium oxide (99.98 atoms \%, MSD Isotopes, Montreal, Canada) was administered as deuterium at $0.014 \mathrm{~g} / \mathrm{kg} /$ body weight. Lean body mass was calculated from the relationship lean body mass = total body water/0.73. Body fat was calculated as body weight minus lean body mass (19). Ideal body weight was defined as the weight percentile corresponding to the height percentile using growth curves for North American children (20) and height/weight tables for adults (21).

Fecal fat excretion was quantitated on entry to the study, from a 3-day stool collection (22), which coincided with the last 3 days of a 7-day dietary record, and expressed as a percentage of fat intake. Blood samples were collected in EDTA at 0 and 6 months of therapy and the plasma stored at $-70^{\circ} \mathrm{C}$ until analyzed for fatty acid profiles. Plasma lipids were extracted in chloroformmethanol (2:1) (23) and separated into cholesterol esters and phospholipids by thin-layer chromatography (24). The fatty acids of the isolated cholesterol esters and phospholipids were determined by gas-liquid chromatography for methyl esters prepared with boron trifluoride (25) as previously described. The retention time of eicosatrienoic acid $(20: \omega 39)$ was established by using plasma from weanling male rats which had received a fat-free diet for 4 wk. A mixture of fatty acids (Applied Sciences Laboratories, State College, PA) of known composition was used as a reference standard for identification of other fatty acids. Essential fatty acid deficiency was defined as decreased linoleic and increased palmitoleic and oleic acids.

Eight North American subjects who were in good health and who ingested a standard North American diet served as controls. Results were analyzed for significance using Student's $t$ test, paired $t$ test and one-way analysis of variance. Where appropriate differences between samples were assessed by the NeumannKreul test and the data expressed as $\overline{\mathrm{x}} \pm$ SEM.

\section{RESULTS}

Three male and five female $C F$ patients with a mean age of $15.1 \mathrm{yr}$ (range 8-27 yr) entered and completed the 6-month study period. There were five patients with, and three without, pancreatic insufficiency. With no exocrine pancreatic supplementation, patients had coefficients of fecal fat excretion $42.7 \pm 5.1 \%$ and $5.0 \pm 1 \%$, respectively. Fat excretion in the former patients decreased to $20 \pm 5.0 \%$ with enzyme administration. The nasogastric tube feedings were well tolerated, with no gastrointestinal symptoms or other complications.

All patients were moderately to severely below ideal body weight on entry to the study. There were significant improvements over the 6-month period in the daily energy intake, body weight, adipose tissue mass, and nonsignificant improvement of lean body mass (Fig. 1). Mean daily intakes of energy, protein, linoleic acid, and zinc at the onset and completion of the study are shown in Table 1 . Subjects demonstrated a significant increase in protein, energy, and zinc intake, whereas linoleic acid intake, expressed either as a percentage of total calories or as an absolute amount, showed no significant change. During the study period, linoleic acid ingestion $(\mathrm{mg} / \mathrm{kg} /$ day) ranged from -8.5 to $99.4 \%$ of initial pretreatment intake.

On entry to the study, the fatty acid composition of plasma lipids differed between CF and control subjects (Table 2). In plasma cholesterol ester fatty acids the relative amount of linoleic acid $(18: 2 \omega 6)$ was decreased whereas palmitic $(16: 0)$, palmitoleic $(16: 1 \omega 9)$, and oleic $(18: 1 \omega 9)$ acids were increased $(p<0.05)$; arachidonic $(20: 4 \omega 6)$ acid was at control levels. In addition, the absolute amount of cholesterol ester fatty acids was decreased; palmitic, oleic, and linoleic acids were significantly less than control levels. The mean triene/tetraene [eicosapentanoic $(20: 3 \omega 9)$ /arachadonic $(20: 4 \omega 6)$ acid] ratio was not significantly different from control levels. In one patient the triene/tetraene

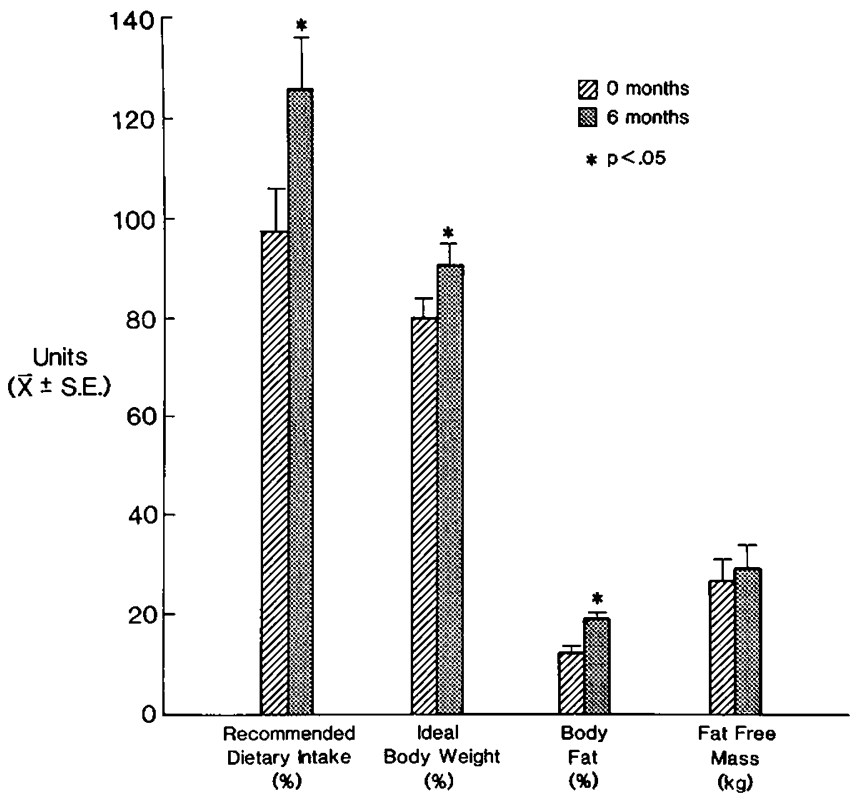

Fig. 1. CF characteristics on entry and end of study.

ratio was more than 0.4 . Plasma phospholipid fatty acids (not shown) mirrored the cholesterol esters.

After 6 months of nutritional rehabilitation, the absolute amount of linoleic acid in the plasma phospholipid of CF patients increased significantly $(p<0.05)$, with six of eight returning to control levels (Fig. 2). The two patients in whom the phospholipid linoleic acid did not reach control levels had steatorrhea and their weight had increased to 85 and $89 \%$ of ideal body weight. Similarly, the cholesterol ester linoleic acid concentration improved significantly with five of eight patients reaching control levels. The sum of the concentrations of the cholesterol ester fatty acids significantly increased during the nutritional rehabilitation period but did not reach control levels; palmitic and oleic acids reached control values whereas palmitoleic acid was increased. When the fatty acids are expressed as the relative amount of the total cholesterol esters fatty acids nutritional support significantly increased linoleic acid whereas oleic acid fell. Nonetheless, linoleic acid remained below control levels and palmitic and palmitoleic remained elevated. The $20: 4 \omega 6 / 18: 2 \omega 6$ ratio decreased, as a result of the nutritional support, but remained elevated compared to control levels. The triene/tetraene ratio fell below 0.4 in the one patient in whom it had been elevated on entry to the study.

The clinical and pulmonary status of these patients before and after nutritional rehabilitation has been reported elsewhere (13). In summary, there was no change in pulmonary status, but sense of well being was improved and hospitalizations for pulmonary infections were decreased.

\section{DISCUSSION}

On entry to the study, the CF patients showed biochemical evidence of a suboptimal EFA status. Reduced tissue levels of linoleic acid were associated with increased palmitoleic and oleic acid. The cause of the abnormal EFA status does not appear to be purely dietary in origin as the intake of linoleic acid in all CF patients, on entry to the study, was above the RDA of $3 \%$ of total calories. The deficit in EFA status also cannot be attributed to decreased fat absorption as three of the eight patients did not have pancreatic insufficiency as they demonstrated normal fecal fat excretion ( $<7 \%$ of intake). Clearly the nutritional therapy was successful in improving body composition and EFA status. Although there was a significant improvement in body weight and EFA status they did not achieve control levels. With im- 
Table 1. Plasma cholesterol fatty acids of control and CF patients at 0 and 6 mo of nutritional rehabilitation*

\begin{tabular}{|c|c|c|c|c|c|c|}
\hline \multirow[b]{2}{*}{ Fatty acid } & \multicolumn{2}{|c|}{ Control } & \multicolumn{2}{|c|}{$0 \mathrm{Mo}$} & \multicolumn{2}{|c|}{$6 \mathrm{Mo}$} \\
\hline & $\%$ & $\mathrm{mg} / \mathrm{dl}$ & $\%$ & $\mathrm{mg} / \mathrm{dl}$ & $\%$ & $\mathrm{mg} / \mathrm{dl}$ \\
\hline $14: 0$ & $1.58 \pm 0.09$ & $1.06 \pm 0.02$ & $1.90 \pm 0.15$ & $0.59 \pm 0.23$ & $2.39 \pm 0.64$ & $1.11 \pm 0.22$ \\
\hline $16: 0$ & $10.40 \pm 0.20$ & $7.13 \pm 0.39$ & $13.78 \pm 0.94 \uparrow^{a}$ & $3.83 \pm 1.05^{a}$ & $14.07 \pm 1.21^{b}$ & $5.37 \pm 0.66$ \\
\hline $16: 1$ & $2.48 \pm 0.19$ & $1.71 \pm 0.17$ & $7.80 \pm 1.96^{a}$ & $1.80 \pm 0.33$ & $7.06 \pm 1.58^{b}$ & $3.51 \pm 0.90^{b, c}$ \\
\hline 18:0 & $1.12 \pm 0.07$ & $0.77 \pm 0.07$ & $1.84 \pm 0.43$ & $0.46 \pm 0.15$ & $1.11 \pm 0.19$ & $0.57 \pm 0.15$ \\
\hline 18:1 & $19.56 \pm 0.96$ & $13.57 \pm 1.25$ & $27.24 \pm 1.24^{a}$ & $7.43 \pm 1.95^{a}$ & $20.20 \pm 1.31^{c}$ & $10.31 \pm 1.66$ \\
\hline $18: 2$ & $55.04 \pm 0.78$ & $37.60 \pm 1.62$ & $34.02 \pm 2.31^{a}$ & $10.80 \pm 3.45^{a}$ & $44.30 \pm 3.28^{b, c}$ & $23.30 \pm 3.95^{b, c}$ \\
\hline $20: 3 \omega 9$ & $0.90 \pm 0.77$ & $0.76 \pm 0.13$ & $1.84 \pm 0.70$ & $0.46 \pm 0.14$ & $1.06 \pm 0.12$ & $0.55 \pm 0.11$ \\
\hline $20: 4$ & $6.99 \pm 0.38$ & $4.74 \pm 0.20$ & $8.70 \pm 0.75$ & $2.91 \pm 1.03$ & $8.11 \pm 0.86$ & $4.10 \pm 0.65$ \\
\hline $22: 6$ & $1.16 \pm 0.23$ & $1.12 \pm 0.14$ & $2.88 \pm 1.15$ & $1.40 \pm 1.04$ & $1.39 \pm 0.45$ & $0.75 \pm 0.23$ \\
\hline Sum $=$ & 100 & $68.5 \pm 62$ & 100 & $29.7 \pm 4.2^{a}$ & 100 & $49.56 \pm 5.1^{b, c}$ \\
\hline \multicolumn{7}{|l|}{ Ratio } \\
\hline $20: 4 / 18: 2$ & $0.11 \pm 0.01$ & & $0.25 \pm 0.2^{a}$ & & $0.19 \pm 0.02^{b, c}$ & \\
\hline $20: 3 \omega 9 / 20: 4 \omega 9$ & $0.15 \pm 0.02$ & & $0.28 \pm 0.16$ & & $0.14 \pm 0.02$ & \\
\hline
\end{tabular}

* Minor fatty acids 14:0, 18:3 $\omega 6,18: 3 \omega 3,20: 3 \omega 6,20: 5 \omega 3,22: 5 \omega 6,22: 5 \omega 3$ not shown.

$\dagger p<0.5$ (control-0 mo $)^{a}$; (control-6 mo $)^{b} ;(0-6 \mathrm{mo})^{c}$.

Table 2. Protein, energy, linoleic acid, and zinc intakes at 0 and 6 mo $(\bar{x} \pm S E)$

\begin{tabular}{|c|c|c|c|c|c|}
\hline \multirow[b]{2}{*}{ Months } & \multirow{2}{*}{$\begin{array}{l}\text { Protein } \\
(\% \text { RDA })\end{array}$} & \multirow{2}{*}{$\begin{array}{c}\text { Energy } \\
\text { (kcal/kg/day) }\end{array}$} & \multicolumn{2}{|c|}{ Linoleic acid } & \multirow{2}{*}{$\begin{array}{c}\text { Zinc } \\
\text { (mg/day) }\end{array}$} \\
\hline & & & $(\mathrm{mg} / \mathrm{kg} /$ day $)$ & (\% kcal) & \\
\hline 0 & $170 \pm 26$ & $80 \pm 12$ & $383 \pm 45$ & $4.50 \pm 0.40$ & $12.66 \pm 5.74$ \\
\hline 6 & $274 \pm 16^{*}$ & $104 \pm 21^{*}$ & $557 \pm 124$ & $4.73 \pm 0.14$ & $20.68 \pm 5.74^{*}$ \\
\hline
\end{tabular}

$* p<0.05$.

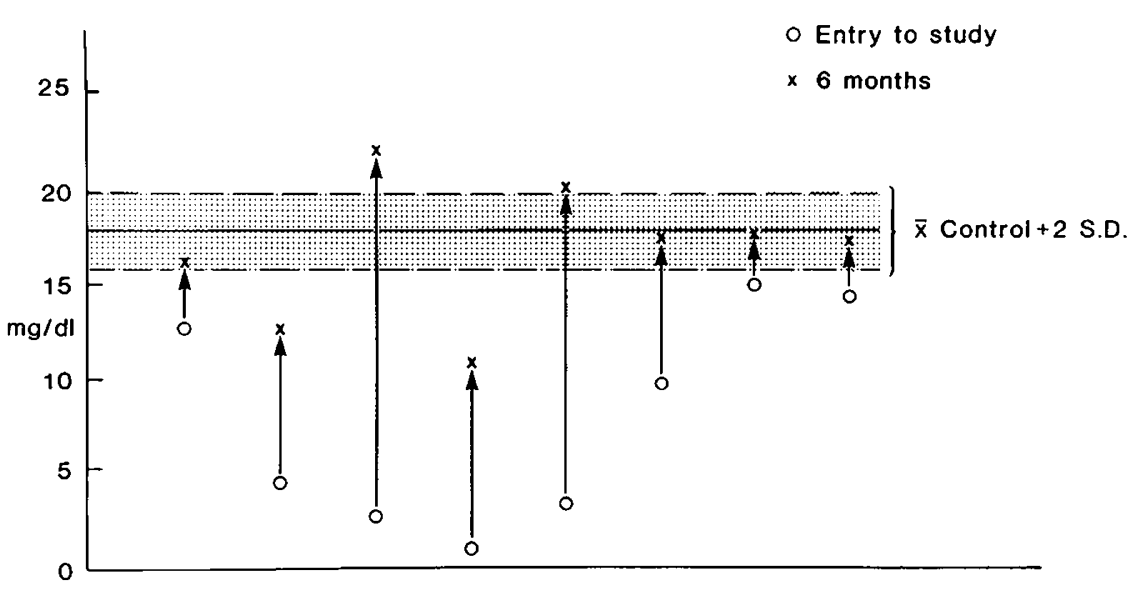

Fig. 2. Plasma phospholipid linoleic acid content (mg/dl) of CF patients on entry and end of study.

provement in body composition the absolute and relative amounts of plasma linoleic acid increased whereas oleic acid decreased. We believe that a longer period of nutritional supplementation would have permitted the achievement of ideal body weight and normalized EFA status.

The plasma fatty acids of the CF patients on entry to the study suggests that the abnormal EFA status is not the result of a pure linoleic acid deficiency. When linoleate is the single nutrient deficiency, its principle metabolite, arachidonic acid $(20: 4 \omega 6)$ is low and the triene/tetraene $(20: 3 \omega 9 / 20: 4 \omega 6)$ ratio is elevated. The elongation desaturation system that converts linoleic acid to arachidonic acid also converts oleic acid to 5,8,11-eicosatrienoic acid $(20: 3 \omega 9)$, but this latter reaction is competitively inhibited by linoleic acid (26). The lack of a significant elevation in the mean triene/tetraene ratio suggests two possible explanations. First, the fall in plasma linoleic acid may not have been large enough to permit conversion of oleic acid to 5,8,11-eicosatrienoic acid. The patient that did have a triene/tetraene ratio of more than 0.4 had the lowest ideal body weight and the lowest plasma linoleic acid level. Second, there are multiple nutritional and hormonal variables that may affect the elongation and desaturation system. For example, in the pure linoleic acid animal model, the expectant rise in 5,8,11-eicosatrienoic acid is delayed and blunted in the presence of a high protein intake (27). Our patients, on entry to the study, were receiving a protein intake well in excess of the RDA. The increased ratio of $20: 4 \omega 6 / 18: 2 \omega 6$ may be a result of decreased arachidonic acid metabolism and/ or a relative increase in the synthesis of arachidonic acid from linoleic acid. Evidence to support the latter hypothesis is the lack of formation of $20: 3 \omega 9$ in the presence of elevated plasma oleic acid and decreased plasma linoleic acid.

The type of nutrient deficiency has a bearing on the fatty acid profile of malnourished patients. This is not unexpected as fatty acid desaturation and elongation enzyme systems are affected by dietary and hormone changes (28). Desaturation of fatty acids is decreased during fasting and protein deficiency $(29,30)$, and increased by a high protein intake (30). Patients with kwashiorkor (protein malnutrition) have decreased plasma levels of linoleic 
and arachidonic acids and increased levels of palmitoleic and oleic acid $(16,31)$. Conversely, patients with marasmus (15) and anorexia nervosa (14) (energy deficiency and adequate protein intake) have a similar fatty acid profile with the exception of normal levels of arachidonic acid. The CF patients, initial fatty acid profile, and dietary intake are characteristic of the latter patients. Our findings support previous reports $(3,32-34)$ of low linoleic with normal arachidonic acids in patients with CF.

Our results suggest that a major cause of the EFA deficiency in malnourished $\mathrm{CF}$ patients is a caloric intake that does not meet metabolic requirements. CF patients tend to have a higher oxygen consumption, and therefore a higher basal metabolic rate, than appropriate controls (12). A decreased energy intake coupled with increased energy needs could lead to oxidation of linoleic acid along with other fatty acids to meet energy needs. This would decrease the availability of linoleic acid for use as an EFA. Corn oil, safflower oil, and linoleic acid monoglyceride have been used in long-term linoleic acid supplementation trials in CF patients. Results were variable but most showed minimal $(7,35)$ or no (36) improvement in EFA status; however, caloric intakes, when reported, were below the RDA for control subjects (7). Improvements of plasma linoleic acid was observed in CF patients when dietary supplementation was directed at increasing calories as well as linoleic acid $(9,37)$. We attribute the improvement in the EFA status of our CF patients to an improved caloric intake in the presence of a linoleic acid intake in excess of the RDA of $3 \%$ of total calories. Although there was not a significant increase in linoleic acid intake during the nutritional rehabilitation, it is apparent that the intake of linoleic acid did increase. Nonetheless, the change in linoleate intake cannot account for the improvement in EFA status in all patients as two subjects improved their EFA status without an increase in the absolute amount of linoleic acid ingested.

Our results also suggest that malabsorption alone is not the sole reason for the EFA deficiency as three of our patients did not have steatorrhea. This finding supports that of McKenna $e t$ al. (38) who showed that when various linoleic acid-containing lipid preparations were administered with pancreatic enzymes to CF patients, mean maximal increase in percent plasma linoleic was no different than controls.

In summary, we conclude that suboptimal caloric intake is an important factor in the development of EFA deficiency in $\mathrm{CF}$ patients. Thus, we would recommend for those CF patients with malnutrition and EFA deficiency: 1) an energy intake of at least $150 \%$ of RDA and 2) linoleic acid supplementation during the recovery phase of at least $5-7 \%$ of total calories-a level two to three times of the RDA-to restore tissue levels (39).

\section{REFERENCES}

1. Kuo PT, Huang NN, Bassett DR 1962 The fatty acid composition of serum chylomicrons and adipose tissue of children with cystic fibrosis of the pancreas. J Pediatr 60:394-403

2. Underwood BA, Denning CR, Navab M 1972 Polyunsaturated fatty acids and tocopheral levels in patients with cystic fibrosis. Ann NY Acad Sci 203:237247

3. Hubbard VS, Dunn GD, di Saint'Agnese PA 1977 Abnormal fatty acid composition of plasma-lipids in cystic fibrosis: a primary and secondary defect? Lancet 2:1302-1304

4. Parsons HG, Shillabeer G, Rademaker AW 1984 Early onset of essential fatty acid deficiency in patients with cystic fibrosis receiving a semisynthetic diet. J Pediatr 105:958-961

5. Holman RT, Johnson S 1981 Changes in essential fatty acid profiles of serum phospholipids in human disease. Prog Lipid Res 20:63-67

6. Rivers JPW, Hassam AG 1975 Defective essential-fatty-acid metabolism in cystic fibrosis. Lancet 2:642-643

7. Lloyd-Still JD, Johnson S, Halman RT 1981 Essential fatty acid status in cystic fibrosis and the effects of safflower oil supplementation. Am J Clin Nutr 34:1-7

8. Hubbard VS, Dunn GD 1980 Fatty acid composition of erythrocyte phospholipids from patients with cystic fibrosis. Clin Chim Acta 102:115-118
9. Landon C, Kerner JA, Castillo R, Adams L, Whalen R, Lewiston NJ 1981 Oral correction of essential fatty acid deficiency in cystic fibrosis. $\mathrm{J}$ Pediatr Gastroenterol Nutr 5:501-504

10. Chase HP, Long MA, Lavin MH 1979 Cystic fibrosis and malnutrition. J Pediatr 95:337-347

11. Parsons HG, Beaudry P, Dumas A, Pencharz PB 1983 Energy needs and growth in children with cystic fibrosis. J Pediatr Gastroenterol Nutr 2:44-49

12. Adeniyi-Jones SK, Suskind R, Kean B, Polombo J, Khaw KT 1979 Growth, energy metabolism and T3 levels in malnutrition in cystic fibrosis. In: Cystic Fibrosis Club Abstracts, p 22

13. O'Loughlin E, Forbes D, Parsons H, Scott B, Cooper D, Gall G 1986 Nutritional rehabilitation of malnourished patients with cystic fibrosis. Am J Clin Nutr 43:732-737

14. Langan SM, Farrell PM 1985 Vitamin E, vitamin A essential fatty acid status of patients hospitalized for anorexia nervosa. Am J Clin Nutr 41:1054-1060

15. Wolfe JA, Margolis S, Bujdoso-Wolfe K, Matusick E, MacLean WC 1984 Plasma and red blood cell fatty acid composition in children with proteincalorie malnutrition. Pediatr Res 18:162-167

16. Naismith DJ $1973 \mathrm{Kwashiorkor}$ in western Nigeria: a study of traditional weaning foods, with particular reference to energy and linoleic acid. $\mathrm{Br} \mathrm{J}$ Nutr 30:567-576

17. Truswell AS, Hansen JDL, Watson CE, Wannenburg P 1969 Relation of serum lipids and lipoproteins to fatty liver in kwashiorkor. Am J Clin Nutr 22:568 576

18. Halliday D, Miller A 1977 Precise measurement of total body water using trace quantities of deuterium oxide. Biochem Mass Spectro 4:82-87

19. Pace N, Rathbun EN 1945 Studies on body composition III. The body water and chemically combined nitrogen content in relation to fat content. J Biol Chem 158:685-691

20. Hamill PVV, Drizd TA, Johnson CL, Reed RB, Roche AF, WM Moore 1979 Physical growth: National Centre for health statistics percentiles. Am J Clin Nutr 32:607-629

21. Anthropometry Report 1980 Nutrition Canada. National Health and Welfare Canada

22. Massion CG, McNeely MD 1973 Accurate micromethod for estimation of both medium- and long-chain fatty acids and triglycerides in fecal fat. Clin Chem 19:499-505

23. Folch J, Lees M, Sloane-Stanley GH 1957 A simple method for the isolation and purification of total lipids from animal tissues. J Biol Chem 226:497509

24. Skipski V, Good JJ, Barclay M, Reggio RB 1968 Quantitative analysis of simple lipid classes by thin layer chromatography. Biochim Biophys Acta 152:10-19

25. Morrison WR, Smith LM 1964 Preparation of fatty acid methyl esters and dimethylacetals from lipids and boronfluoride-methanol. J Lipid Res 5:600608

26. Brenner RR 1971 The desaturation step in the animal biosynthesis of polyunsaturated fatty acids. Lipids 6:567-575

27. Hill EG, Holman RT 1980 Effect of dietary protein level upon essential fatty acid (EFA) deficiency. J Nutr 100:1057-1060

28. de Gomez Dumm INT, de Alaniz MJT, Brenner RR 1976 Comparative effect of glucagon, dibutyryl cyclic AMP, and epinephrine on the desaturation and elongation of linoleic acid by rat liver microsomes. Lipids 11:833-836

29. Sprecher H 1974 The influence of dietary alterations, fasting and competitive interactions on the microsomal chain elongation of fatty acids. Biochim Biophys Acta 360:113-123

30. De Tomas ME, Mercuri O, Rodrigo A 1980 Effects of dietary protein and EFA deficiency on liver 5,6 and 9 desaturase activities in the early developing rat. J Nutr 100:595-599

31. Naismith DJ 1973 Kwashiorkor in western Nigeria: a study of traditional weaning foods, with particular reference to energy and linoleic acid. $\mathrm{Br} \mathrm{J}$ Nutr 30:567-576

32. Chase HP, Dupont $J 1978$ Abnormal levels of prostaglandins and fatty acids in blood of children with cystic fibrosis Lancet 2:236-238

33. Rogiers V, Vercruysse A, Dab I, Baran D 1983 Abnormal fatty acid pattern of the plasma cholesterol ester fraction in cystic fibrosis patients with and without pancreatic insufficiency. Eur J Pediatr 141:39-42

34. Rogiers V, Crokaert R, Vis H-L 1980 Altered phospholipid composition and changed fatty acid pattern of the various phospholipid fractions of red cell membranes of cystic fibrosis children with pancreatic insufficiency. Clin Chim Acta 105:105-115

35. Kussofsky E, Strandvik B, Troell S 1983 Prospective study of fatty acid supplementation over 3 years in patients with cystic fibrosis. $J$ Pediatr Gastroenterol Nutr 2:434-438

36. Roselund ML, Selekman JA, Kim HK, Kritchevsky D 1977 Dietary essential fatty acids in cystic fibrosis. Pediatrics 59:428-432

37. Mischler EH, Parrell SW, Farrell PM, Raynor WJ, Lemen RJ 1986 Correction of linoleic acid deficiency in cystic fibrosis. Pediatr Res 20:36-41

38. McKenna MC, Hubbard VS, Bieri JG 1985 Linoleic acid absorption from lipid supplements in patients with cystic fibrosis with pancreatic insufficiency and in control subjects. J Pediatr Gastroenterol Nutr 4:45-51

39. Joint FAO/WHO ad hoc Expert Committee on Dietary Fat and Oils in Human Nutrition 1978 Rome: FAO Food and Nutrition 